\author{
KATARZYNA PAPAJA \\ Uniwersytet Śląski
}

\title{
The role of a teacher in a CLIL classroom
}

\begin{abstract}
CLIL classrooms are not typical language classrooms due to the fact that language is the medium through which content is "transported". Non-linguistic content is used to teach a language and learners acquire new knowledge but in a foreign language. The following paper provides an outline of research on the role of a teacher in a CLIL classroom. Starting with a brief insight into the phenomenon of CLIL, and a general overview of the qualitative studies based on observations, questionnaires and interviews, the article focuses particularly on the main features of a CLIL teacher.
\end{abstract}

KEYWORDS: CLIL, bilingual, language classroom, teacher, teaching, language development.

\section{INTRODUCTION}

The role of a teacher in a CLIL classroom is extremely important. The CLIL teacher should have the qualities that Whitty (1996: 89-90) enumerates, namely: "professional values, professional development, communication, subject knowledge, understanding of learners and their learning". Additionally, the CLIL teacher should have the ability to teach one or more subjects in the curriculum in a language other than the usual language of instruction and moreover, teach that language itself (Eurydice 2006). Teachers involved in CLIL should also recognise the need to change established habits which might be used in the L1 when teaching the same content in L2.

In the following article, I am going to discuss the role of a teacher in a CLIL classroom. I strongly believe that apart from the CLIL learner, the CLIL teacher is a central 'element' in determining success in learning subjects through another language. Firstly, I will enumerate the main features of a CLIL teacher. Secondly, I will present the methods and instruments of data collection and discuss the results of the study. The empirical study based on observations and interviews with the teachers was conducted over a period 
of one school year at secondary schools in which various subjects are offered in English. All the schools which took part in the study are situated in the southern part of Poland (Silesia and Little Poland). The total number of teachers who took part in the study was 31. Finally, I will draw some conclusions and provide suggestions concerning the improvement of bilingual education in Poland.

\section{A CLIL TEACHER}

Teachers involved in CLIL recognise the need to change established habits which might be used in the L1 when teaching the same content in L2. What is evident is that a professional teacher will recognise that the CLIL context means that it is not only the teacher's linguistic competence which is of importance, but also that of the learners. This leads directly to the notion of methodological shift. The main characteristic of this shift lies in the movement from teacher-centred to learner-centred methods.

It is also very important for those teachers who know that their linguistic skills are limited to adapt their content and methods accordingly. Marsh et al. (2001: 78) claim that "this is where code-switching and preparation become crucial". On the other hand, Hall (2001: 120) states that "it is very important to remember that being able to use a L2 does not mean being able to teach in that L2 in a given situation". If a CLIL teacher is to teach extensively in the L2 it is essential that she/he has sufficient command of the language.

Marsh et al. (2001: 78-80) outline the 'idealised competencies' required of a CLIL teacher:

a) LANGUAGE/COMMUNICATION

- sufficient target language knowledge and pragmatic skills for CLIL,

- sufficient knowledge of the language used.

b) THEORY

- comprehension of the differences and similarities between the concepts of language learning and language acquisition.

c) METHODOLOGY

- ability to identify linguistic difficulties,

- ability to use communication/interaction methods that facilitate the understanding of meaning,

- ability to use strategies (e.g. repetition, echoing etc. ...) for correction and for modelling good language usage,

- ability to use dual-focussed activities which simultaneously cater for language and subject aspects.

d) THE LEARNING ENVIRONMENT

- ability to work with learners of diverse linguistic/cultural backgrounds. 
e) MATERIALS DEVELOPMENT

- ability to adapt and exploit materials,

- ability to select complementary materials on a given topic.

f) ASSESSMENT

- ability to develop and implement evaluation and assessment tools.

One of the most important abilities of the CLIL teacher is second language competence. Andrews (1999: 163) argues that "the teacher of a language, like any educated user of that language, undoubtedly needs levels of implicit and explicit knowledge of grammar which will facilitate effective communication". At the same time, however: "effective L2 teaching requires of the teacher more than just the possession of such knowledge and the ability to draw upon it for communicative purposes. The L2 teacher also needs to reflect upon that knowledge and ability, and upon his/her knowledge of the underlying systems of the language, in order to ensure that the learners receive maximally useful input for learning" (Andrews 1999).

Teaching in CLIL demands much more than the ability to speak or listen in a particular language. Whether one is dealing with native or non-native speakers of a given language, the key question of linguistic competence for the teaching context remains a key issue. Good linguistic skills in the target language are necessary. Teachers who use CLIL need to be linguistically aware, possessing insight into how language functions, in addition to being able to use the language as a tool in the classroom. What is very important is that those teachers who know their linguistic skills are limited need to adapt their content and methods. In fact, "this is where code-switching and preparation become crucial" (Marsh, Marsland 1999: 45). It is also reasonable to suggest that teachers with more limited linguistic skills have to pay more attention to lesson planning in order to feel more confident.

Generally speaking, CLIL teachers need to be simultaneously both language and content teachers. The emphasis may be more towards one of these than the other, depending on the teacher competences but nonetheless "dual-interest and dual-ability, if not dual-qualification, appear to be highly desirable" (Marsh, Marsland 1999: 38).

According to Eurydice (2006), in the CLIL type provision, teachers are specialists in one or more non-language subjects or have two areas of specialisation, one in a language subject and the other in a non-language subject. However, there are countries in which the teachers do not have dual education and therefore they need to provide a certified evidence of particular skills. None of the diplomas or certificates required relates to CLIL type provision as such, or more specifically to particular aspects of its teaching principles and methodology. 
According to the latest regulations (2004) regarding teacher training standards in Poland, all graduates should master a foreign language and have reached level B2 or B2+ of the Council of Europe Common European Framework of Reference for Languages (2001). In addition, teachers are now obliged to specialise in a second subject. If they choose the combination 'non-language subject plus foreign language', they have to reach level C2 of the Common European Framework of Reference for Languages, in the case of the language subject (Eurydice 2006).

\section{A BRIEF DESCRIPTION OF THE STUDY}

The study, which lasted one school year, was conducted in secondary and lower secondary schools where various subjects are offered in English. 31 Polish teachers of the bilingual subjects participated in the study. They were teachers of Geography, Biology Mathematics, Physics and History. Their teaching experience differed as well as their educational background. All were fully qualified teachers with university degrees in a particular subject and teaching experience at secondary school or lower secondary level, varying from 3 years to 10 years. Only four were fully qualified teachers with additional university degree in English; The other completed some courses in English and passed additional exams allowing them to teach a subject through English. All the teachers were observed while teaching in English (5 lessons per week) and all of them were interviewed. The questions were open-ended and they were connected with bilingual education. The answers presented below are the most common ones provided by the CLIL teachers.

\section{THE RESULTS OF THE STUDY}

In the following part of this article, I am going to present the questions asked in the interview and also discuss the answers given by the teachers.

1. Is there a recognised need to create more bilingual classes in the school?

All the CLIL teachers interviewed answered that there was a need to create more bilingual classes in the school in which they were working as the knowledge of English language was not enough in today's world. They all said that knowledge about particular subjects in a foreign language was very crucial.

2. Over the year, what proportion of English language (texts, teacher talk, student-to-student - holistic appraisal) is used in a bilingual lesson? 
Geography - about $90 \%$

Biology - about $90 \%$

History - about $80 \%$

Mathematics - about $40 \%$

Physics - about $20 \%$

Having taken into consideration the data from class observations, the proportion of English language used during CLIL classes was around 90\% in the case of Geography and Biology, 80\% in History, 40\% in Mathematics and $20 \%$ in Physics. The reason why only between $40 \%$ and $20 \%$ of English language is used during Mathematics and Physics can be connected with the fact that scientific subjects are concerned to be more difficulty even in the native language.

3. Are you actively doing in-service professional development or likewise?

Most of the CLIL teachers took part in bilingual workshops organised in Warsaw and Torun. The Geography CLIL teachers and the Biology CLIL teachers took part in some conferences on ecology. Two Physics teachers participated in a CLIL training organised in Great Britain.

It is very good that the CLIL teachers take part in bilingual workshops as it helps them to develop professionally and exchange teaching experiences with other CLIL teachers.

4. Are the bilingual classes more directed towards European and international orientation than Polish-medium classes within the school?

The bilingual classes are rather Polish-medium oriented due to the fact that the CLIL learners are obliged to take their final secondary school examination ("Matura") in Polish.

5. How is the content affected by the use of the foreign language?

All the CLIL teachers interviewed answered that content was NOT affected by the use of the foreign language but it required more effort and time both on the part of the teacher and the learner.

6. Are you a different teacher in English than in Polish? Why/why not?

The answers provided by the teachers varied:

- "No, the lesson looks the same" (Mathematics, Physics);

- "Yes, it's different - I introduce a lot of English vocabulary, translate certain aspects into Polish and do less exercises because there is not time" (Geography);

- "Yes, I am. I try to use certain methods which are used in the language classroom, e.g. PW or GW" (biology);

- "Yes, I try to teach the language as well" (History)

As it can be seen from the answers provided, the Geography, Biology and History CLIL lessons differed from the ones in Polish while the Mathematics and Physics CLIL lessons were very similar, which was visible during observations. 
7. What professional needs do you have when teaching through English (if any)?

The most common answers were the following:

- "To be a good teacher";

- "To have more teaching materials (films, presentations, articles etc.)";

- "To have a course book for Geography in English"

- "To have materials in English preparing for the final examination (e.g. a set of exercises)";

- "To have good students who want to study hard";

- "I would like to be better paid";

- "I wish there were more teacher training organised";

- "I need some support from other teachers";

- "A special curriculum for the bilingual stream of education";

- "Student and teacher exchanges between bilingual school";

As it can be seen from the data, the CLIL teachers have different needs some of them are connected with professional development, some with the learners and some with financial needs.

8. What are the motivating factors as far as teaching in a bilingual classroom is concerned?

The teachers enumerated the following motivating factors:

- "learners' achievements - they are able to speak, e.g. about bones in English or they take part in language competitions which they win";

- "learners future achievements at foreign Universities";

- "the possibility to improve my own knowledge in a foreign language";

- "a lot of possibilities, e.g. trips abroad, meeting foreigners, exchanges etc";

9. What are the de-motivating factors as far as teaching in a bilingual classroom is concerned?

The teachers enumerated the following de-motivating factors:

- "lack of teaching materials";

- "lack of financial support";

- "lack of teacher training concerning CLIL methodology and some established criteria for the creation of teaching materials";

- "lack of agendas for schools";

- "lack of teacher cooperation as far as sharing materials is concerned";

- "teaching materials created for native speakers which are often too difficult to use in the early years of a CLIL course";

As it can be seen from the data provided above, the teachers listed more de-motivating factors than the motivating ones. These factors are mostly connected with extrinsic motivation. Hopefully, these factors will not dominate the motivating factors which are mainly intrinsic ones. 


\section{CONCLUSION}

Recent discussions have maintained that CLIL offers opportunities to improve the process of language learning and language teaching. "CLIL theoreticians and teachers claim that the learning environment created by CLIL increases the learner's general learning capacities, his/her motivation and interest" (Wolff 2005: 9). There is much discussion about the global spread of English as a medium of education. There have been major achievements over the last twenty years in how to teach English as a second/foreign language. Some approaches to subject teaching have developed radically, others less so. This is also the case with how teachers teach. The following suggestions should be taken into consideration in Polish bilingual education:

- As far as the choice of the teaching method is concerned, the CLIL teachers should aim at a combination of content and language focused instruction, which would enable the CLIL learners to use language for genuine communication as well as to attain a high level of content accuracy;

- The CLIL teachers should be careful not to take up most of the available speaking time with their explanations or instructions so the CLIL learners will have an opportunity to have more practice in their target language;

- The CLIL teachers should use the mother tongue only when they find it necessary;

- All the CLIL teachers should be able to join professional networks connected with bilingual education which could help them with exchanging ideas with other CLIL teachers from all over the world;

- The CLIL teachers should be provided with opportunities to develop their second language proficiency in all skills as well as to take part in teacher training devoted to bilingual education;

- The teachers should be encouraged to use the European Language Portfolio and also work with the Common European Framework of References for Languages;

- The teachers, as well as the learners, should be provided with some preparation materials for Matura in English as well as with mock exams;

\section{REFERENCES}

Andrews, B.W., 1999. Side by side: Evaluating a partnership program in arts teachereducation. In: International Electronic Journal of Leadership, 3 (16). Available at: <http:/ / www.ucalgary. ca/-iejll/> (date of access: 19. 11. 2011) 
Council of Europe, 2001. The Common European Framework of Reference for Languages. Cambridge: Cambridge University Press.

Eurydice, 2006. Content and Language Integrated Learning (CLIL) at School in Europe. Brussels: Eurydice European Unit.

Hall, R.E. 2001. Identity development across lifespan: a biracial model. The Social Science Journal, 38, 119-123.

Marsh, D., Marsland, B. (eds). 1999. Learning with Languages. A professional Development Programme for Introducing Content and Language Integrated Learning. Finland: University of Jyväskylä, 30-48.

Marsh, D., Maltjers, A., Hartiala, A. (eds), 2001. Profiling European CLIL Classrooms - Languages Open Doors. Finland: University of Jyväskylä, 78-91.

Papaja, K., 2010. A Qualitative Evaluation of Content and Language Integrated Learning (CLIL) in Secondary Education. Unpublished PhD thesis. Katowice: Institute of English, University of Silesia.

Whitty, G., 1996. Creating Quasi-Markets in Education: A review of recent research on Parental choice and school autonomy in three countries. Review of Research in Education, 22, 89-95.

Wolff, D., 2003. Content and language integrated learning: a framework for the development of learner autonomy. In: Little, D., Ridley, J., Ushioda E. (eds). Learner Autonomy in the Foreign Language Classroom: Teacher, Learner, Curriculum and Assessment, Dublin: Authentik, 211-222.

Wolff, D., 2005. Content and Language Integrated Learning. Handbook of Applied Linguistics [HAL], Vol. 5, Chapter 21, 1-22. 